\title{
Health Care Provider Effective Date Range
}

National Cancer Institute

\section{Source}

National Cancer Institute. Health Care Provider Effective Date Range. NCI Thesaurus.

Code C93842.

The date and time span for when the healthcare provider is active. 